\title{
Afferent baroreflex failure and tako-tsubo cardiomyopathy
}

\author{
Lucy J. Norcliffe-Kaufmann • Harmony R. Reynolds
}

Published online: 15 January 2011

(C) Springer-Verlag 2011

Tako-tsubo is a Japanese fisherman's octopus trapping pot. The word has become popular to describe a type of cardiomyopathy in which the left ventricle of the heart transiently balloons at the apex and mid portions and, with a little imagination, looks like a tako-tsubo [1]. Variant forms of transient left ventricular dysfunction in which the apex is not affected have also been described [2]. Additional names for this clinical syndrome are transient left ventricular dysfunction syndrome, stress cardiomyopathy or apical ballooning cardiomyopathy. Patients present similarly to those with myocardial infarction, typically with chest pain and dyspnea and with findings on electrocardiography which are characteristic of myocardial infarction such as ST segment elevation and $\mathrm{T}$ wave inversion [3-5]. However, elevation of cardiac biomarkers such as troponin is modest and, in addition, the coronary arteries show no flow-limiting stenosis on conventional angiography [3]. Tako-tsubo cardiomyopathy resolves spontaneously and nearly all patients completely recover within a few weeks [6]. Thus, tako-tsubo cardiomyopathy may be considered to represent myocardial "stunning" rather than a permanent injury.

What is so special about this peculiar ballooning of the heart? First, it affects women much more often than men, and perhaps most intriguingly, it occurs frequently after a catastrophic emotional stress, such as an earthquake [7] or

L. J. Norcliffe-Kaufmann ( $₫)$

Department of Physiology and Neuroscience, New York

University School of Medicine, New York, NY, USA

e-mail: lucynorcliffe@gmail.com

H. R. Reynolds

Cardiovascular Clinical Research Center, Leon H. Charney Division of Cardiology, Department of Medicine, New York University School of Medicine, New York, USA the unexpected death of a close friend or relative $[3,4]$. Of course, events that occur after emotionally charged situations are always suspected to be caused by high levels of catecholamines, both norepinephrine, the neurotransmitter of the sympathetic nervous system, and epinephrine, the hormone that classically increases with stress. Indeed, patients with tako-tsubo cardiomyopathy have a 30-fold increase in their plasma levels of norepinephrine and epinephrine, which is substantially higher than the increase seen in patients with acute myocardial infarction [4]. Moreover, cases of tako-tsubo cardiomyopathy have been reported following intravenous infusion of epinephrine [8] or norephinephrine [9] as well as in patients with pheochromocytoma who have endogenous catecholamine surges [10-12]. Furthermore, microscopic analysis of myocardium in patients with tako-tsubo syndrome may show contraction band necrosis and focal inflammatory infiltrates, as seen in syndromes of catecholamine excess [13]. Recently, analysis of endomyocardial biopsies taken from patients who have tako-tsubo cardiomyopathy has shown alteration in expression of the sarcoplasmic reticulum calcium ATPase and dephosphorylation of phospholamban, changes which suggest overstimulation of myocardial beta adrenoceptors in this syndrome [14].

In this issue of clinical autonomic research Berganzo et al. suggest a possible link between afferent baroreflex dysfunction and tako-tsubo cardiomyopathy. This is not surprising. Normally, increases in sympathetic activity are restrained by the baroreflexes, which are classic negative feedback loops. Afferent baroreflex dysfunction (also called baroreflex failure to distinguish it from autonomic efferent failure) is a neuro-visceral disorder that selectively affects the relay of afferent baroreceptor information from the carotid sinus and aortic arch to the nucleus tractus solitarius (NTS) in the brainstem [15-17]. In patients with 
afferent baroreflex failure, cortical arousal evokes unrestrained surges in circulating catecholamines accompanied by profound hypertension and tachycardia and frequently severe headaches and flushing [15-17].

The case reported by Berganzo et al. features a 37-yearold woman who developed palpitations and shortness of breath while jogging. On admission to the emergency room, she had electrocardiographic ST changes and modestly elevated cardiac enzymes. Echocardiogram showed global hypokinesis of the left ventricle and coronary angiogram revealed no evidence of coronary artery disease. An MRI of the brain revealed bilateral lesions in the dorsomediolateral region of the medulla, involving the NTS, presumably the result of an acute disseminated encephalomyelitis associated with her Mycoplasma pneumoniae infection. Although the pattern of left ventricular dysfunction was atypical for transient left ventricular dysfunction syndrome due to lack of preservation of contractile function at the base of the heart; there was, however, full recovery of normal function is as typical in this disorder.

If indeed this was tako-tsubo cardiomyopathy, the triggering stress that increased sympathetic activity in this case was exercise, which in a patient with afferent baroreflex failure can be particularly dangerous. In addition to the so-called central command, a CNS mechanism that increases sympathetic activity during exercise, mechanical and metabolic stimuli from the contracting muscles evoke a reflex increase in muscle sympathetic outflow [18]. Information from the contracting muscle is conveyed to the brain via the spinal cord in afferent nerve fibers with cell bodies in the dorsal root ganglia. By taking this route, this information bypasses the classic afferent baroreflex pathways, and increases efferent sympathetic outflow without directly involving the NTS. This case highlights the dangers of exercising without the normal inhibitory loop. It is tempting to speculate that patients with tako-tsubo cardiomyopathy have a subtle abnormality in their afferent baroreflex pathways that makes them susceptible to catecholamine-induced myocardial stunning.

Acknowledgments L. J. N-K receives research support from the NIH (U54NS065736) and the FDA (FD-R-3731-01). H. R. R is a recipient of a Doris Duke Clinical Scientist Development Award.

\section{References}

1. Lyon AR, Rees PS, Prasad S, Poole-Wilson PA, Harding SE (2008) Stress (takotsubo) cardiomyopathy-a novel pathophysiological hypothesis to explain catecholamine-induced acute myocardial stunning. Nat Clin Pract Cardiovasc Med 5:22-29

2. Kurowski V, Kaiser A, von Hof K, Killermann DP, Mayer B, Hartmann F, Schunkert H, Radke PW (2007) Apical and midventricular transient left ventricular dysfunction syndrome (tako-tsubo cardiomyopathy): frequency, mechanisms, and prognosis. Chest 132:809-816

3. Tsuchihashi K, Ueshima K, Uchida T, Oh-mura N, Kimura K, Owa M, Yoshiyama M, Miyazaki S, Haze K, Ogawa H, Honda T, Hase M, Kai R, Morii I (2001) Transient left ventricular apical ballooning without coronary artery stenosis: a novel heart syndrome mimicking acute myocardial infarction. Angina pectorismyocardial infarction investigations in Japan. J Am Coll Cardiol 38:11-18

4. Wittstein IS, Thiemann DR, Lima JA, Baughman KL, Schulman SP, Gerstenblith G, Wu KC, Rade JJ, Bivalacqua TJ, Champion HC (2005) Neurohumoral features of myocardial stunning due to sudden emotional stress. N Engl J Med 352:539-548

5. Bybee KA, Kara T, Prasad A, Lerman A, Barsness GW, Wright RS, Rihal CS (2004) Systematic review: transient left ventricular apical ballooning: a syndrome that mimics ST-segment elevation myocardial infarction. Ann Intern Med 141:858-865

6. Desmet WJ, Adriaenssens BF, Dens JA (2003) Apical ballooning of the left ventricle: first series in white patients. Heart 89: $1027-1031$

7. Watanabe H, Kodama M, Okura Y, Aizawa Y, Tanabe N, Chinushi M, Nakamura Y, Nagai T, Sato M, Okabe M (2005) Impact of earthquakes on takotsubo cardiomyopathy. JAMA 294:305-307

8. Manivannan V, Li JT, Prasad A, Campbell RL (2009) Apical ballooning syndrome after administration of intravenous epinephrine during an anaphylactic reaction. Mayo Clin Proc $84: 845-846$

9. Subramaniam A, Cooke JC, Ernest D (2010) "Inverted" takotsubo cardiomyopathy due to exogenous catecholamines. Crit Care Resusc 12:104-108

10. Di Palma G, Daniele GP, Antonini-Canterin F, Piazza R, Nicolosi GL (2010) Cardiogenic shock with basal transient left ventricular ballooning (takotsubo-like cardiomyopathy) as first presentation of pheochromocytoma. J Cardiovasc Med (Hagerstown) 11:507-510

11. Rossi AP, Bing-You RG, Thomas LR (2009) Recurrent takotsubo cardiomyopathy associated with pheochromocytoma. Endocr Pract 15:560-562

12. Sanchez-Recalde A, Costero O, Oliver JM, Iborra C, Ruiz E, Sobrino JA (2006) Images in cardiovascular medicine. Pheochromocytoma-related cardiomyopathy: inverted takotsubo contractile pattern. Circulation 113:e738-e739

13. Nef HM, Mollmann H, Kostin S, Troidl C, Voss S, Weber M, Dill T, Rolf A, Brandt R, Hamm CW, Elsasser A (2007) Takotsubo cardiomyopathy: intraindividual structural analysis in the acute phase and after functional recovery. Eur Heart $\mathrm{J} 28$ : 2456-2464

14. Nef HM, Mollmann H, Troidl C, Kostin S, Voss S, Hilpert P, Behrens CB, Rolf A, Rixe J, Weber M, Hamm CW, Elsasser A (2009) Abnormalities in intracellular $\mathrm{Ca}^{2+}$ regulation contribute to the pathomechanism of tako-tsubo cardiomyopathy. Eur Heart J 30:2155-2164

15. Biaggioni I, Whetsell WO, Jobe J, Nadeau JH (1994) Baroreflex failure in a patient with central nervous system lesions involving the nucleus tractus solitarii. Hypertension 23:491-495

16. Norcliffe-Kaufmann L, Axelrod F, Kaufmann H (2010) Afferent baroreflex failure in familial dysautonomia. Neurology 75:19041911

17. Robertson D, Hollister AS, Biaggioni I, Netterville JL, MosquedaGarcia R, Robertson RM (1993) The diagnosis and treatment of baroreflex failure. N Engl J Med 329:1449-1455

18. Kaufman MP, Rotto DM, Rybicki KJ (1988) Pressor reflex response to static muscular contraction: its afferent arm and possible neurotransmitters. Am J Cardiol 62:58E-62E 